Disponível em:

http://editora.unoesc.edu.br/index.php/race

Race, Joaçaba, v. 14, n. 3, p. 1063-1090, set./dez. 2015

\title{
ANÁLISE DO DESEMPENHO FINANCEIRO DAS EMPRESAS DO SETOR DE ÓLEO \& GÁS POR MEIO DO COMPORTAMENTO DOS FLUXOS DE CAIXA NO PERÍODO DE 2010 A 2013
}

\section{The Financial Performance Evaluation Of The Oil and Gas Industry Through The Cash Flow Indicators In The Period From 2010 to 2013}

Sophie de Souza Abrahão

E-mail:sophieabrahao@hotmail.com Mestranda do Programa de Pós-Graduação em Ciências Contábeis da Universidade Federal do Rio de Janeiro; Graduada em Ciências Contábeis pela Universidade Federal do Rio de Janeiro

Rua São Francisco Xavier, 524, $9^{\circ}$ andar, Bloco E, Maracanã, 20550-013, Rio de Janeiro, RJ, Brasil.

Márcia da Silva Carvalho E-mail: carvalho93@hotmail.com Doutora em Ciências, em Planejamento Energético - Área de Concentração: Planejamento Ambiental; Mestre em Ciências Contábeis pela Universidade do Estado do Rio de Janeiro; Professor adjunto I da Universidade Federal do Rio de Janeiro.

\section{José Augusto Veiga da Costa Marques}

E-mail: joselaura@uol.com.br

Pós-doutor em Contabilidade e Controladoria pela Universidade de São Paulo; Doutor em Administração de Empresas pela Escola de Administração de Empresas

pela Fundação Getulio Vargas; Professor Associado da Universidade Federal do

Rio de Janeiro

Artigo recebido em 11 de novembro de 2014. Aceito em 08 de junho de 2015 


\section{Resumo}

A presente pesquisa discorre sobre alguns dos indicadores obtidos por meio da demonstração dos fluxos de caixa, enfatizando os que relacionam o total do caixa gerado/consumido nas atividades operacionais. Foram selecionadas 10 companhias abertas listadas na SEC do setor de óleo \& gás, que divulgam anualmente suas demonstrações no formato 20-F, nos anos 2010 a 2013. Foram escolhidas as companhias mais relevantes considerando-se seu valor de mercado. Os dados utilizados na pesquisa foram obtidos da base de dados do site PFC Energy, sendo estruturados de maneira que fosse possível analisar o comportamento dos fluxos de caixa por meio de gráficos. Mediante a análise, foi perceptível que a amostra obedeceu a padrões de crescimento e redução semelhantes em quase todas as categorias analisadas ao longo dos quatro anos, fato que não foi observado apenas em relação ao indicador de qualidade do resultado, em que nenhum padrão consistente foi encontrado. Também foi perceptível que, para a maior parte das companhias analisadas, 2011 foi o ano em que elas obtiveram os maiores lucros líquidos e, consequentemente, os maiores valores de dividendos pagos e os maiores montantes de FCO.

Palavras-chave: Contabilidade financeira. Fluxo de caixa. Indicadores financeiros. Análise de quocientes. Contabilidade de petróleo e gás.

\section{The Financial Performance Evaluation Of The Oil and Gas Industry Through The Cash Flow Indicators In The Period From 2010 to 2013}

\section{Abstract}

This study focuses on some of the cash flow indicators, emphasizing those that relate the total cash generated/ consumed from operating activities. Were selected 10 Oil and Gas public companies listed on SEC, that disclose their statements annually in F-20 form in the period from 2010 to 2013. The companies were selected taking the market value into consideration to choose the most relevant ones. The data applied in this research were obtained through the PFC Energy database, being structured in a way that was possible to analyze the behavior of cash flows through graphs. Through analysis, it was noticeable that the sample obeyed similar patterns of growth and reduction in almost all categories analyzed over the four years, fact that was not observed only in the indicator of quality of the result, which no logical pattern was found. It was also noticeable that for most of the analyzed companies, 2011 was the year in which they obtained the largest net profits, and, consequently, higher values of dividends paid and the biggest OCF results.

Keywords: Financial Accounting. Cash Flow. Financial ratios. Quotients analysis. Oil E gas accounting.

\section{INTRODUÇÃO}

Intencionou-se, com o presente estudo, analisar o desempenho financeiro das 10 principais empresas integradas do setor de óleo e gás, por meio de indicadores 
obtidos mediante a demonstração dos fluxos de caixa (DFC), no período de 2010 a 2013.

No atual mercado financeiro, cada vez mais competitivo, exigem-se das organizações informações mais precisas e seguras para embasar decisões financeiras. Para Assaf Neto e Silva (1997), o fluxo de caixa se destaca como um instrumento capaz de possibilitar o planejamento e o controle dos recursos financeiros de uma organização, proporcionando ao gestor meios de sugerir, quando necessário, modificações em procedimentos adotados pela empresa, bem como tomar decisões que condizem com as demandas da organização.

A demonstração dos fluxos de caixa (DFC), passou a ser um relatório financeiro obrigatório para todas as sociedades de capital aberto com patrimônio líquido superior a dois milhões de reais por força da Lei n. 11.638/07, cuja obrigatoriedade passou a vigorar a partir de 01 de janeiro de 2008 . O Pronunciamento Técnico CPC 26 inclui a DFC como parte do conjunto completo das demonstrações contábeis, ao passo que o CPC 03 é o pronunciamento técnico que dispõe sobre essa demonstração, como principal finalidade proporcionar informações que permitam a avaliação da estrutura financeira da organização - como a sua liquidez e solvência -, assim como avaliar mudanças ocorridas nos ativos líquidos da entidade.

Segundo Braga e Marques (2001), várias medidas de desempenho podem ser alcançadas a partir da DFC, em especial as que relacionam fluxo de caixa gerado/ consumido pelas atividades operacionais normais da organização a algum item específico. Os autores propõem que a análise seja feita por meio de quatro categorias de indicadores: cobertura de caixa; qualidade do resultado; dispêndios de capital e retornos do fluxo de caixa.

Ferraes Neto (2002) afirma que o cálculo e a interpretação dos índices financeiros são uma das formas mais utilizadas para avaliar o desempenho de uma empresa; já Gitman (1997) enfatiza que a análise dos indicadores não é meramente a aplicação de uma forma sobre dados financeiros para calcular determinado índice, o mais importante é a interpretação do valor desse índice.

Em relação ao exposto, o objetivo geral com esta pesquisa foi evidenciar, por meio do cálculo de quatro indicadores extraídos daquelas categorias de quocientes da demonstração dos fluxos de caixa, a situação financeira das 10 maiores empresas integradas do setor de óleo \& gás, no período de 2010 a 2013.

Como objetivos específicos, pretende-se aplicar os indicadores financeiros de desempenho nas demonstrações dos fluxos de caixa da amostra e buscar explicações econômicas para o comportamento dos indicadores calculados. Não 
representa objetivo com este estudo contrastar exaustivamente as empresas, de modo que a comparação acontece de maneira tênue mediante os resultados obtidos pelos indicadores.

Para alcançar os objetivos, realizou-se uma pesquisa de caráter descritivo, já que com o presente trabalho se expõem características dos fluxos de caixa das 10 maiores empresas integradas do setor de óleo \& gás.

A pesquisa buscou calcular e analisar quatro indicadores financeiros, a fim de responder ao seguinte questionamento: como os indicadores obtidos por meio da DFC podem ser utilizados na análise de liquidez e solvência de empresas petrolíferas?

Diante do exposto, justifica-se o atual estudo pela importância que o setor petrolífero exerce na economia mundial, sendo um dos setores mais rentáveis e lucrativos, além de ser uma das principais matrizes energéticas utilizadas mundialmente. O estudo também se justifica à medida que amplia a discussão sobre os indicadores financeiros obtidos por meio da DFC, que auxiliam investidores e demais interessados a terem uma visão mais nítida sobre a situação financeira de uma empresa ou de determinado setor.

Quanto às delimitações e limitações, pode-se citar o fato de que foram analisadas apenas as 10 principais companhias integradas do setor de óleo \& gás, excluindo empresas de médio e pequeno portes, fato que impossibilita generalizações. Além disso, outro aspecto reside no fato de que foram calculados e analisados apenas os índices referentes aos anos 2010 a 2013, restringindo o estudo a um período de quatro anos.

O trabalho está estruturado em cinco seções, incluindo esta introdução. A segunda seção apresenta a revisão da literatura pertinente, trazendo o referencial teórico que embasa o estudo. A terceira seção expõe a metodologia da pesquisa, os dados são apresentados e analisados na quarta seção. Por fim, a quinta seção exibe as considerações finais - discussões e conclusões - sobre o estudo.

\section{ESTUDOS ACERCA DA DFC}

Beaver (1968) buscou em sua pesquisa descobrir medidas contábeis alternativas para a previsão de falência. Seu estudo tinha como propósito enfatizar a necessidade de verificação empírica de uma crença, citando áreas em que esta estava comprovadamente errada, e definir um método para avaliar empiricamente as 
medidas contábeis alternativas. Foram analisadas 79 empresas falidas e 79 não falidas, totalizando 158 companhias, entre os anos 1954 e 1964, utilizando 14 indicadores financeiros em cada uma das empresas.

Segundo o autor, indicou-se, com este estudo, que os indicadores calculados com base nos fluxos de caixa avaliam melhor a situação financeira das empresas, sendo mais eficazes para prever falências que os índices calculados por meio do capital circulante líquido. A pesquisa revelou que a relação entre o fluxo de caixa e o total da dívida é capaz de melhor prever insolvência com cinco anos de antecedência. Foi observado, também, que a análise do indicador do fluxo de caixa operacional sobre as dívidas totais foi relevante por ter melhor capacidade relativa de prever falências.

Largay III e Stickney (1980) analisaram a falência da maior empresa de varejo dos EUA, a W. T. Grant Company. A companhia americana de comércio varejista abriu concordata em outubro de 1975, falindo quatro meses depois, em fevereiro de 1976. O estudo evidenciou que uma análise desenvolvida mediante índices tradicionais das demonstrações financeiras (DFs), da companhia não teria indicado a existência de muitos problemas financeiros até o período de 1970 a 1971.

Os índices de rentabilidade, rotação, liquidez e solvência, calculados por meio de dados obtidos das demonstrações financeiras da Grant, não revelavam nenhuma dificuldade financeira em relação à empresa ao longo dos 10 anos anteriores à falência. Porém, os autores observaram que a companhia apresentou problemas para conseguir gerar caixa internamente ao longo desses anos. Fato curioso, já que em 1973 os autores observaram que as ações da Grant Company apresentavam um valor de venda aproximado de 20 vezes o lucro. Com a contínua incapacidade de geração de caixa por meio de suas operações, a Grant se viu obrigada a recorrer a financiamentos externos, gerando cada vez mais dívidas. Assim, os autores concluíram que uma análise minuciosa nos fluxos de caixa da empresa teria indicado a falência da companhia aproximadamente uma década antes do colapso.

Rushinek e Rushinek (1987) exploraram a viabilidade de utilizar índices financeiros como uma técnica analítica para prever insolvências financeiras. Pretendiam, com o estudo, avaliar a qualidade das análises. Logo, para avaliar com precisão o potencial, os autores combinaram um conjunto de índices financeiros com a análise discriminante, para que fosse possível prever a insolvência financeira em um período de três anos. Utilizando a análise discriminante, foi fixada uma pontuação de risco de crédito para determinar se o credor deve ou não aceitar o possível mutuário. O estudo revelou que o modelo foi efetivo em $80 \%$ dos casos. 
Dechow, Kothari e Watts (1998) desenvolveram um modelo de fluxo de caixa operacional e um processo formal de contabilidade em que esses fluxos de caixa fossem convertidos em lucro contábil. O modelo implica que rendimentos conseguem prever melhores fluxos de caixa operacionais futuros do que os fluxos de caixa operacionais atuais, em que a diferença entre eles varia de acordo com o ciclo de caixa operacional. A amostra compreendia 1337 empresas, entre os anos 1963 e 1992. Os autores concluíram que o atual rendimento de uma empresa é a melhor previsão de fluxos de caixa futuros, superando os fluxos de caixa atuais, como foi previsto no modelo estudado. Os autores também afirmam que a diferença na capacidade dos lucros correntes e fluxos de caixa atuais em prever fluxos de caixa futuros são funções positivas do ciclo de caixa operacional da empresa.

Givoly e Hayn (2000) documentaram as mudanças nos padrões de lucro, fluxo de caixa e provisões ao longo de quatro décadas, a fim de descobrir se os relatórios financeiros estavam se tornando cada vez mais conservadores com o passar do tempo. Os autores relataram uma série de medidas consideradas conservadoras e as examinaram, chegando à conclusão de que as referidas medidas dependem da acumulação de provisões não operacionais (resultados descontinuados), da oportunidade de ganhos em relação a uma boa/má notícia, das características de distribuição de rendimentos e da diferença entre o valor de mercado e o valor contábil. Logo, por meio da pesquisa, chegaram à conclusão de que houve um aumento de informações financeiras mais conservadoras ao longo do tempo, principalmente entre as duas últimas décadas analisadas no estudo.

Em sua pesquisa, Braga e Marques (2001) buscaram demonstrar a viabilidade das análises financeiras feitas a partir de dados obtidos da DFC mediante um estudo sobre a avaliação de liquidez das empresas. Os autores classificaram alguns dos índices obtidos da DFC em quatro categorias distintas, com propósitos variando da avaliação da capacidade de pagamento do negócio até a determinação das taxas de recuperação de caixa.

Para que os objetivos fossem alcançados, os autores calcularam e analisaram os quocientes extraídos dos relatórios publicados pelas empresas Companhia Vale do Rio Doce (CVRD) e Centrais Elétricas de Minas Gerais (CEMIG), entre os anos 1997 e 1999. Por meio dos resultados obtidos, os autores concluíram que os quocientes extraídos a partir de dados da DFC fornecem informações relevantes a respeito da situação financeira das companhias, mesmo que os referidos índices sofram as mesmas limitações que os índices convencionais, quando usados de maneira isolada e para períodos curtos de tempo. 
Jooste (2006) comparou indústrias africanas e norte-americanas químicas, de alimentos e de eletrônicos, por meio do cálculo de nove indicadores de desempenho obtidos por intermédio dos fluxos de caixa, entre os anos 1986 e 1988. A comparação revelou que o índice de suficiência do fluxo de caixa demonstrou que as indústrias africanas tinham dinheiro suficiente para pagar as suas obrigações, enquanto as indústrias norte-americanas não. Em relação aos níveis de caixa gerados pelas indústrias africanas, os investimentos em ativos e pagamentos de dividendos foram maiores para elas do que para as indústrias norte-americanas. O fluxo de caixa gerado por meio dos ativos das indústrias africanas também foi maior do que para as norte-americanas, porém, demonstrou com o estudo que estas conseguem quitar suas dívidas de longo prazo em um período mais curto do que as africanas. Ao comparar as indústrias de um país em desenvolvimento com as de um país desenvolvido, o autor quis apurar o desempenho das indústrias africanas em um mercado global.

Alves e Marques (2007) analisaram o comportamento dos fluxos de caixa de seis companhias abertas do setor de papel e celulose, a fim de identificar a fase do ciclo de vida em que cada uma delas se encontrava, buscando, assim, definir um perfil para as empresas brasileiras do referido setor entre os anos 2000 e 2005. Por meio de uma equação de variação de caixa, foram estabelecidos parâmetros para medir o comportamento das seis empresas, por meio de dados obtidos da DFC. Os ciclos de vida foram classificados em quatro fases: introdutória, de crescimento, de maturidade e de declínio. Ao fim da pesquisa, a comparação revelou que entre as empresas estudadas, a maior parte se encontrava em fase de maturidade. Como a amostra estudada foi considerada representativa, os autores chegaram à conclusão de que o perfil das companhias abertas brasileiras do setor de papel e celulose, entre os anos 2000 e 2005, é de maturidade.

Duhovnik (2008) centrou-se sobre o valor adicional que as informações contábeis podem fornecer aos usuários das demonstrações preparadas com base no fluxo de caixa. O autor se baseou na constatação de que a literatura profissional é inconsistente ao tentar distinguir liquidez e as informações sobre rentabilidade, o que acaba afetando também a distinção entre os índices calculados pelas referidas bases. $\mathrm{O}$ autor concluiu que a qualidade da informação contábil pode ser significativamente melhorada caso a demonstração dos fluxos de caixa seja preparada por meio do método direto baseado em rastreamento em vez de calcular o real fluxo de caixa. Assim, os índices obtidos por meio do fluxo de caixa serviriam como um 
mecanismo de controle das premissas utilizadas na preparação das demonstrações financeiras.

Bastos et al. (2009) verificaram as relações entre quatro medidas de desempenho comumente utilizadas pelas empresas e pelo mercado - Lucro por Ação, Retorno sobre o Investimento, Valor Econômico Adicionado (EVA) e Fluxo de Caixa Operacional - por meio de uma amostra de 93 companhias abertas não financeiras que atuam no Brasil, entre os anos 2001 e 2007. O estudo buscou testar a importância dos indicadores de desempenho na criação de valor para os acionistas e a relevância do EVA em comparação a outras métricas.

Os autores demonstraram que as métricas escolhidas apresentavam um baixo poder explicativo sobre o retorno das ações, sendo o Fluxo de Caixa Operacional o indicador que obteve o melhor resultado na análise, e o EVA o que apresentou o pior resultado, o que fez com que a hipótese de superioridade dessa medida de desempenho que considera o custo de capital na análise de criação de valor fosse descartada.

Barac (2010) procurou evidências empíricas sobre o conteúdo de informação incremental de índices de fluxo de caixa e índices de medida de desempenho das empresas. O estudo indica que a avaliação de desempenho dos negócios com base em índices de fluxo de caixa obtém informações mais precisas e confiáveis do que as avaliações baseadas em índices por competência. A amostra da pesquisa incluía demonstrações financeiras anuais de empresas listadas na Croácia, entre os anos 2000 e 2006, cujo resultado indicou que as informações obtidas por meio do fluxo caixa e dos índices de fluxos de caixa são mais relevantes que as informações obtidas por meio do balanço patrimonial e da demonstração de resultado ao analisar empresas. $\mathrm{O}$ autor ressalta que a DFC se tornou uma ferramenta muito importante de análise financeira para as companhias.

Barbosa et al. (2010) demonstraram em sua pesquisa a relevância da análise das DFCs para a tomada de decisões dos gestores, no que se refere ao planejamento operacional e estratégico da organização. Para que o propósito fosse atingido, foram calculados os índices econômico-financeiros apor meio dos dados obtidos na DFC da empresa Sadia S.A. O estudo foi delimitado para analisar apenas as demonstrações da empresa Sadia, publicadas entre 2007 e 2008, e os resultados alcançados apontaram a extrema importância da DFC como ferramenta de gestão de recurso da empresa, e, consequentemente, grande aliada para a tomada de decisões dos gestores e usuários da informação financeira. Porém, os autores recomendam que seja feita uma análise conjunta dos indicadores obtidos da DFC com os demais 
oriundos de outros demonstrativos, para que seja possível analisar profundamente a situação econômico-financeira da companhia.

Macedo et al. (2011) investigaram, por meio de análises de regressão, o impacto causado pela substituição da Demonstração das Origens e Aplicações (DOAR) pela DFC, que foi implementada no Brasil em razão das mudanças ocorridas nas normas contábeis brasileiras vigentes, passando a vigorar a partir de 2008. Foi analisada a questão do value relevance das origens de recursos das operações (OROPA) resultantes da DOAR e do fluxo de caixa operacional (FCOPA), oriundos da DFC, das empresas não financeiras de capital aberto listadas na base de dados Melhores e Maiores da FIPECAFI-EXAME, entre os anos 2005 e 2007. Evidências empíricas apontaram que o fluxo de caixa operacional (FCOPA) é mais relevante que as OROPAs para o mercado de capitais, o que se conclui, segundo os autores, que a substituição da DOAR pela DFC foi benéfica para os usuários da informação contábil no Brasil, o que pode ser justificado pelo fato de a DFC ser uma demonstração de fácil compreensão, fazendo com que ela seja mais utilizada.

Em sua pesquisa, Francis (2011) fornece evidências empíricas de que as distribuições de caixa líquido para os acionistas proporcionam um contexto de melhoria notável para a previsão futura de fluxos de caixa. $\mathrm{O}$ estudo levantou a hipótese de que a exatidão das previsões futuras aumenta de acordo com a magnitude das distribuições líquidas feitas aos acionistas. Os resultados empíricos foram consistentes com essa hipótese para previsões com um ano de antecedência, obtendo resultados condizentes com a dimensão dos controles da companhia. O autor afirma que, no geral, o estudo fornece um contexto prático para analistas, credores e outros, pelo fato de gerar previsões de fluxo de caixa.

Em seu artigo, Xu (2012) desenvolveu duas hipóteses para identificar como a remuneração baseada em ações afeta a sensibilidade da gestão dos fluxos de caixa das empresas: uma baseada na teoria da agência e a outra na teoria da assimetria de informação. Segundo o autor, as empresas reagem às mudanças de fluxo de caixa de três formas principais: investimentos, participações em dinheiro e pagamentos. $\mathrm{O}$ autor concluiu que os resultados empíricos obtidos são consistentes com a segunda hipótese, da assimetria de informação. Quando a gerência tem remuneração baseada em ações, a empresa passa a ter maior sensibilidade no fluxo de investimento de dinheiro, maior sensibilidade no fluxo de caixa e menor sensibilidade no fluxo de pagamentos em dinheiro.

No Brasil, Borges, Nunes e Alves (2012), prosseguindo o estudo feito por Barac (2010), compararam a informação financeira obtida por meio de indicadores 
calculados a partir de dados preparados com base nos pressupostos da contabilidade de caixa e da contabilidade por competência (accruals). Foram obtidos dados por meio de relatórios e contas de 82 empresas nos anos 2005 a 2009. O estudo demonstrou que a utilização da DFC com as demais demonstrações financeiras auxilia profundamente na tomada de decisões. Os autores conseguiram demonstrar, mediante análises, que tanto o modelo baseado nos indicadores de competência, quanto o modelo com base nos indicadores dos fluxos de caixa são eficazes para prever a situação futura de classificação de uma empresa.

Farshadfar e Monem (2013) investigaram se os componentes do fluxo de caixa operacional obtido pelo método direto possuem maior capacidade preditiva para fluxos de caixa futuros do que o fluxo de caixa operacional agregado. A pesquisa utilizou uma amostra de 348 empresas australianas, entre os anos 1992 e 2004. Os autores explicam que a escolha por empresas australianas ocorreu pelo fato de que a publicação da DFC pelo método direto no país é obrigatória desde 1992. Os resultados obtidos sugerem que a elaboração da DFC pelo método direto melhora a capacidade preditiva do fluxo de caixa operacional agregado, para um horizonte de previsão de quatro anos. Os autores também constataram que os recebimentos de clientes e o montante pago a fornecedores e colaboradores se completam quando o objetivo é prever componentes do fluxo de caixa.

Assim, pode-se afirmar que a DFC é considerada um importante instrumento de apoio à tomada de decisão, e que quando analisada em conjunto com as demais demonstrações, é capaz de fornecer dados relevantes e precisos para seus usuários.

\section{METODOLOGIA}

De acordo com o objetivo geral, proposto neste estudo, a pesquisa pode ser classificada como descritiva, uma vez que se pretendeu calcular e analisar as quatro categorias de indicadores de desempenho financeiro obtidos por meio de dados da demonstração dos fluxos de caixa das 10 empresas escolhidas do setor de óleo \& gás no período de 2010 a 2013.

Com a pesquisa descritiva, na concepção de Gil (1999), tem-se o objetivo de descrever características de determinada população ou fenômeno, ou estabelecer relações entre variáveis. Sua característica mais relevante é a utilização de técnicas padronizadas para a coleta de dados. 
Andrade (2002) afirma que a pesquisa descritiva se preocupa em observar, registrar, analisar, classificar e interpretar os fatos, sem que o pesquisador interfira neles.

Os procedimentos técnicos utilizados nesta pesquisa se caracterizam como documentais, bibliográficos e ex-post-facto.

A pesquisa documental, para Vergara (1998, p. 46), “[...] é realizada em documentos conservados no interior de órgãos públicos e privados de qualquer natureza [...]" Silva e Grigolo (2002) afirmam que a pesquisa documental utiliza materiais que não obtiveram nenhuma análise aprofundada, fazendo com que esse tipo de pesquisa busque selecionar, tratar e interpretar uma informação bruta, procurando extrair dela algum sentido ou valor. Logo, a pesquisa documental é justificada pelas consultas às DFCs, disponibilizadas no site da Securities and Exchange Commission (SEC), assim como pela busca de informações sobre companhias de óleo \& gás em sites especializados.

A pesquisa bibliográfica, segundo Gil (1999), é desenvolvida por meio de material já elaborado, em especial livros e artigos científicos. Assim, ela se justifica em razão da relevância da fundamentação teórica sobre o assunto tratado, assim como da importância de se manter atualizada em relação aos artigos científicos, dissertações e normatizações pertinentes.

A pesquisa ex-post-facto "[...] refere-se a um fato já ocorrido. Aplica-se quando o pesquisador não pode controlar ou manipular variáveis [...]” (VERGARA, 1998, p. 47). O enquadramento da pesquisa é justificado pelo fato de as DFCs analisadas serem referentes aos anos 2010 a 2012, eventos já ocorridos e divulgados.

A amostra da pesquisa consiste no extrato das 10 maiores companhias abertas listadas na $S E C$ do setor de óleo \& gás, que divulgam anualmente suas demonstrações no formato 20-F, nos anos 2010 a 2013. Todas são integradas, ou seja, atuam em toda a cadeia produtiva de petróleo, da produção à distribuição. A amostra é não probabilística, pois não utiliza qualquer forma aleatória de seleção. Vergara (1998, p. 49) afirma que a amostra não probabilística se subdivide em duas categorias: por acessibilidade e por tipicidade. A autora define a seleção por tipicidade como "[...] constituída pela seleção de elementos que o pesquisador considere representativos da população-alvo [...]" Na presente pesquisa, a amostra foi definida por tipicidade, em que foram selecionadas as 10 principais e mais influentes companhias do setor de óleo \& gás listadas na SEC.

Foi apurado que as companhias mais relevantes, em relação ao valor de mercado, encontram-se na Tabela 1 , a seguir. 
Tabela 1 - Principais empresas do setor de óleo \& gás segundo seu valor de mercado e respectivas localizações

\begin{tabular}{rlrl}
\hline $\begin{array}{c}\text { Ranking } \\
\text { em 2012 }\end{array}$ & \multicolumn{1}{c}{ Empresa } & $\begin{array}{c}\text { Valor de mercado } \\
\text { (em bilhóes de } \\
\text { dólares) }\end{array}$ & $\begin{array}{c}\text { Localização } \\
\text { - Sede }\end{array}$ \\
\hline 1 & ExxonMobil Co. & 394.6 & EUA \\
2 & PetroChina Co. Ltd. & 264.5 & China \\
3 & Royal Dutch Shell PLC & 222.6 & Holanda \\
4 & Chevron Co. & 211.6 & EUA \\
5 & BP PLC & 132.1 & Reino Unido \\
6 & Ecopetrol S.A. & 126.6 & Colômbia \\
7 & Petrobras S.A. & 124.7 & Brasil \\
8 & TOTAL S.A. & 121.9 & França \\
9 & Gazprom & 112.3 & Rússia \\
10 & CNOOC Ltd. & 96.7 & China \\
11 & Sinopec Petrochemical Co. Ltda. & 96.5 & China \\
\hline
\end{tabular}
Fonte: adaptado de PFC Energy (2013).

A amostra é considerada representativa para o setor, por conter as principais companhias produtoras de óleo \& gás do mundo. Os dados aplicados foram obtidos da base de dados do site Petroleum Finance Company (PFC Energy) e foram estruturados por empresa, para que fosse possível analisar o comportamento dos seus fluxos de caixa por meio de gráficos desenvolvidos mediante planilhas do programa Excel.

A Tabela 1 lista as 11 principais empresas do setor de óleo \& gás pelo fato de que a companhia russa Gazprom, que ocupa a nona posição no ranking elaborado pelo PFC Energy, não está listada na $S E C$, fato que inviabilizou sua utilização na pesquisa.

A comparação será quantitativa - série histórica de cada organização, pois irá analisar as quatro categorias de indicadores de desempenho financeiros obtidos por meio de dados da demonstração dos fluxos de caixa.

O quadro 1, a seguir, lista por categoria os indicadores que foram utilizados para se obterem os resultados da pesquisa. Eles foram selecionados por serem os que mais dispunham de dados das referidas empresas na base de dados do PFC Energy. 
Quadro 1 - Indicadores utilizados na amostra

\begin{tabular}{|l|l|l|}
\hline $\begin{array}{l}\text { Categoria 1 - Quocientes } \\
\text { de cobertura de caixa }\end{array}$ & $\begin{array}{l}\text { Cobertura de Dividendos com } \\
\text { Caixa = FCO/Dividendos Pagos }\end{array}$ & $\begin{array}{l}\text { Permite avaliar a } \\
\text { capacidade da com- } \\
\text { panhia de pagar seus } \\
\text { dividendos. }\end{array}$ \\
\hline $\begin{array}{l}\text { Categoria 2 - Quocientes } \\
\text { de qualidade do resultado }\end{array}$ & $\begin{array}{l}\text { Qualidade do Resultado = FCO/ } \\
\text { LAJIR } \\
\text { resultado operacional } \\
\text { - antes dos resul- } \\
\text { tados financeiros e } \\
\text { do imposto sobre a } \\
\text { renda - gerou de caixa } \\
\text { operacional. }\end{array}$ \\
\hline $\begin{array}{l}\text { Categoria 3 - Quocientes } \\
\text { de dispêndios de capital }\end{array}$ & $\begin{array}{l}\text { Investimento/Financiamento }= \\
\text { timentos/Fluxo de Caixa Líquido } \\
\text { de Financiamentos + Fluxo de } \\
\text { Caixa Líquido Operacional }\end{array}$ & $\begin{array}{l}\text { Permite evidenciar } \\
\text { como os investi- } \\
\text { mentos vêm sendo } \\
\text { financiados. }\end{array}$ \\
\hline $\begin{array}{l}\text { Categoria 4 - Retornos } \\
\text { do fluxo de caixa }\end{array}$ & $\begin{array}{l}\text { Retorno do Caixa Sobre os Ativos } \\
\text { = FCO/Ativos Totais }\end{array}$ & $\begin{array}{l}\text { Permite avaliar o } \\
\text { retorno obtido sobre o } \\
\text { investimento total. }\end{array}$ \\
\hline
\end{tabular}

Fonte: os autores.

Quanto às limitações do estudo, pode-se citar o fato de terem sido estudadas apenas as 10 principais companhias integradas do setor de óleo \& gás, excluindo empresas de médio e pequeno portes, impossibilitando generalizações. Além disso, outra limitação reside no fato de que foram apenas calculados e analisados os índices referentes aos anos 2010 a 2013, o que restringe a avaliação a esse período de tempo, bem como o fato de que a base de dados utilizada no estudo - PFC Energy - mantém as contas das companhias excessivamente agregadas, fato que pode ter prejudicado a determinação exata de alguns dos quocientes.

\section{APRESENTAÇÃO E ANÁLISE DOS RESULTADOS}

\subsection{PANORAMA DO SETOR PETROLÍFERO DE 2010 A 2013}

A crise econômica que abalou a economia mundial em 2008 e 2009 estremeceu o setor energético, tendo a situação econômica mundial começado a apresentar sinais de melhora apenas no ano 2010, quado o consumo de energia global se recuperou fortemente. Durante o ano em questão, o mundo estava começando a emergir da pior crise econômica vista em décadas. 
Dados da British Petroleum PLC (2011) afirmam que o consumo total de energia durante 2010 aumentou 5,6\% em relação ao ano anterior, fato que possibilitou que o valor atual superasse o pico alcançado durante a pré-recessão de 2008/2009.

Durante o período de recessão global, a Organização dos Países Exportadores de Petróleo (OPEP) diminuiu sua produção, fato que se estendeu até 2011, e que acarretou um significativo aumento nos preços do óleo como consequência da forte recuperação do consumo pós-recessão.

Em razão dos cortes de produção da OPEP - implementados em 2008/2009, mas ainda em vigor em 2011 -, durante 2011, os preços médios do petróleo para o ano foram os segundos maiores em registro. Ainda, em 2011, a China conseguiu ultrapassar os Estados Unidos como o maior consumidor de energia do mundo.

O forte crescimento do consumo do petróleo, aliado à contenção de produção da OPEP, ajudaram a fazer com que durante 2011 o preço do petróleo crescesse cada vez mais, chegando a um pico de US\$94,00 no final do ano.

Em 2011 alguns acontecimentos agitaram o cenário da energia global, como a "Primavera Árabe", que abalou o mercado de energia após um importante campo petrolífero localizado no Leste da Síria passar a ser controlado pelos rebeldes islâmicos, fato que demonstrou a todos a importância de se manter a capacidade de reposição e também os estoques estratégicos para poder lidar com possíveis rupturas no abastecimento. $\mathrm{O}$ terremoto seguido do tsunâmi ocorrido no Japão também impactou o setor energético global; após o ocorrido, os preços do petróleo bateram o maior recorde de todos os tempos.

Porém, dados referentes ao consumo mundial de energia da British Petroleum PLC (2012) demonstraram que após o pico observado no consumo durante o período pós-recessão, o setor não conseguiu sequer manter seu ritmo de crescimento, registrando assim valores bem abaixo nos anos seguintes.

\subsection{COMPORTAMENTO DOS FLUXOS DE CAIXA DAS EMPRESAS SELECIONADAS}

A British Petroleum PLC é uma multinacional sediada no Reino Unido que atua no setor de energia, principalmente na área de petróleo e gás. Ela é considerada uma das maiores empresas desse setor no mundo, oferecendo desde combustíveis e lubrificantes até energia e produtos petroquímicos. 
A British Petroleum PLC aumentou relativamente sua geração de fluxos de caixa das atividades operacionais entre os anos 2010 e 2011, o que contribuiu para a elevação do nível de solvência durante esse período, fato que não ocorreu em 2012, quando surgiu uma pequena diminuição deste, e em 2013, quando a companhia obteve apenas um pequeno aumento. Durante os anos 2010 e 2011, as atividades de financiamento da companhia geraram caixa, fato que não ocorreu em 2012 e 2013, quando houve uma saída líquida desse fluxo. Destaca-se o ano 2013, quando a referida saída foi aproximadamente cinco vezes maior que a de 2012 . Em relação aos fluxos de caixa das atividades de investimento, houve um aumento expressivo das saídas em 2011, fato que foi reduzido em 2012 e 2013.

Com sede nos Estados Unidos, a Chevron Corporation é uma das maiores empresas integradas de energia do mundo. Sua ênfase é no setor petrolífero, no qual atua em diversas áreas, como exploração, produção, refino, comercialização e distribuição do petróleo, gás natural e seus derivados.

Em relação à geração de fluxos de caixa das atividades operacionais, a Chevron teve um aumento entre os anos 2010 e 2011, o que indica aumento nas operações da empresa e uma ligeira diminuição de forma gradativa dela em 2012 e 2013. Entre os anos 2010 e 2011, a companhia mais que dobrou a geração de caixa das atividades de financiamento, fato que não ocorreu em 2012, em razão de uma pequena redução do fluxo gerado, e em 2013, quando a redução das atividades de financiamento foi significativa. Já os fluxos de caixa das atividades de investimento tiveram seu ápice de crescimento durante 2013.

A China National Offshore Oil Corporation (CNOOC Limited) é uma empresa petrolífera semiestatal chinesa, na qual o acionista majoritário é o Governo chinês, que controla $70 \%$ de suas ações. Considerada a maior produtora de petróleo offshore e gás natural da China, a companhia obtém cerca de $80 \%$ dos seus rendimentos pela exploração petrolífera direta.

A CNOOC quase dobrou a geração de caixa por meio das suas operações entre os anos 2010 e 2011, fato que não conseguiu acompanhar em 2012, obtendo melhorias apenas em 2013. Em relação ao fluxo de caixa das atividades de financiamento, a companhia consumiu quase 15 vezes mais caixa em 2011 do que em 2010, fato que foi totalmente modificado em 2012 e 2013, quando a empresa reverteu esse quadro, passando a gerar entradas líquidas. No ano 2013, a companhia gerou entradas sete vezes maiores que as de 2012. O caixa gerado nas atividades de investimento foi sempre presente, tendo o seu ápice de aumento de saída de caixa em 2013. 
Sediada na Colômbia, a Ecopetrol S.A. é uma sociedade de economia mista sob a forma jurídica de uma sociedade anônima. É a maior empresa petrolífera da Colômbia, sendo o Governo colombiano detentor de $80 \%$ das suas ações. A companhia conta com 32 blocos explorados apenas em território colombiano, assim como com uma rede de $8.500 \mathrm{~km}$ de dutos para transporte dos hidrocarbonetos.

Os fluxos de caixa das atividades operacionais da Ecopetrol tiveram um aumento significativo entre 2010 e 2011, o que contribui para uma melhora nos níveis de solvência da companhia. Em relação às atividades de financiamento, houve uma elevação gradual de saídas líquidas, fato que não ocorreu com as saídas referentes às atividades de investimento, que teve seu ponto mais elevado durante 2011.

A ExxonMobil Corporation é uma companhia multinacional atuante no setor de óleo \& gás. Considerada a empresa privada n. 1 do mundo do setor de petróleo e petroquímicos, é o principal fornecedor mundial de óleos-base para lubrificantes e também o maior comerciante de lubrificantes acabados.

A ExxonMobil teve um aumento notório em seus fluxos de caixa das atividades operacionais durante os três primeiros anos analisados, fato que demonstra a ampliação de suas operações e também age de maneira positiva nos índices de solvência do negócio. Porém, em 2013, foi notória a redução do referido fluxo em aproximadamente 10 milhões. Em relação às atividades de financiamento, é possível notar um aumento do consumo de caixa de maneira gradual durante 2010 e 2012, assim como uma significativa redução em 2013, fato que não se repete com os fluxos de caixa das atividades de investimento, que teve um declínio apenas no ano 2011.

A Petróleo Brasileiro S.A., a Petrobras, é uma sociedade anônima de capital aberto controlada pelo Governo brasileiro. Empresa de energia, tornouse reconhecida internacionalmente pela excelência mundial no desenvolvimento e na aplicação de tecnologia de exploração e produção em águas profundas e ultraprofundas.

Em relação aos fluxos de caixa das atividades operacionais, 2011 foi o ano em que a Petrobras obteve maior geração de caixa. Os fluxos de caixa das atividades de financiamento geraram caixa durante os quatro anos analisados, tendo uma drástica redução das entradas líquidas entre os anos 2010 e 2011. Já as atividades de investimentos tiveram uma significativa redução entre 2010 e 2011, seguidas de um modesto aumento nas saídas de caixa no ano 2012 e de uma pequena redução em 2013. 
A PetroChina Company Limited é o maior produtor e distribuidor de petróleo e gás da China, considerada uma das empresas com maior receita de vendas do país. A companhia foi estabelecida como uma sociedade por ações com responsabilidade limitada por parte da China National Petroleum Corporation (CNPC), e seus negócios abrangem todos os setores-chave da indústria de petróleo e gás.

A PetroChina teve seu ápice de crescimento de geração de fluxo de caixa das atividades operacionais durante 2011, tendo uma considerável redução em 2012, recuperada durante 2013. Quanto às atividades de financiamento, houve geração de caixa em suas operações, exceto em 2010 e 2013, anos em que ocorreu consumo de caixa - saídas líquidas. As atividades de financiamento permaneceram estáveis durante os quatro anos analisados, tendo uma melhora em 2012.

A Royal Dutch Shell PLC, ou simplesmente Shell, é uma multinacional anglo-holandesa atuante no setor de energia e petroquímica. Com mais de 87.000 mil trabalhadores espalhados em mais de 70 países, a companhia está organizada em três áreas: Upstream, Downstream e Projetos \& Tecnologias, área responsável pelo gerenciamento de grandes projetos e criação de soluções tecnológicas por meio de pesquisas e inovações.

Em relação à geração de fluxos de caixa das atividades operacionais, a Shell registrou um aumento praticamente proporcional durante os quatro anos analisados, fato que contribui para elevar os níveis de solvência da companhia. Os fluxos de caixa das atividades de financiamento tiveram um grande aumento de 2010 para 2011, ano que atingiu o ápice de caixa consumido. Curiosamente, os fluxos de caixa das atividades de investimento se comportaram de maneira contrária ao das atividades de financiamento, tendo o seu menor valor registrado no ano 2011.

A Sinopec Petrochemical Company Limited é uma empresa de energia chinesa que fornece produtos químicos e derivados do petróleo. Ela é considerada uma das maiores petroquímicas integradas da China, sendo um dos mais importantes produtores nacionais de produtos refinados de petróleo, produtos petroquímicos intermediários, resinas e fibras sintéticas.

A Sinopec manteve sua geração de caixa das atividades operacionais praticamente estável entre os anos 2010 e 2013, tendo apenas em 2012 uma pequena diminuição. Quanto às atividades de financiamento, a companhia reduziu seu caixa entre 2010 e 2012, fato que ocorreu mais drasticamente em 2011. Contudo, em 2013, a empresa aumentou de forma expressiva seu caixa, cinco vezes maior que o do ano anterior. A partir de 2012, houve geração líquida de caixa. As saídas líquidas 
de caixa das atividades de investimento foram sempre presentes, aumentando a cada ano.

A TOTAL S.A. é um grupo empresarial francês do setor petroquímico e energético que conta com mais de 97.000 funcionários, tendo operações em mais de 130 países. Ela está organizada em três grandes segmentos: Upstream, Refino \& Químicos e Markting \& Serviços, os quais abrangem o fornecimento e a comercialização dos produtos petrolíferos.

A TOTAL aumentou gradativamente sua geração de fluxos de caixa das atividades operacionais durante os quatro anos analisados. Quanto ao fluxo de caixa das atividades de financiamento, manteve-se praticamente estável entre 2010 e 2012, tendo uma ligeira diminuição em 2013. As saídas líquidas de caixa das atividades de investimento tiveram um aumento durante os quatro anos analisados, permanecendo estáveis apenas entre os anos 2011 e 2012.

\subsection{ANÁLISE DOS INDICADORES}

O Gráfico 1, a seguir, revela a análise da primeira categoria dos indicadores, de quocientes de cobertura de caixa, calculados por meio do índice de cobertura de dividendos pagos com caixa para todas as companhias analisadas, entre os anos 2010 e 2013.

Gráfico 1 - Índice de cobertura de dividendos pagos com caixa

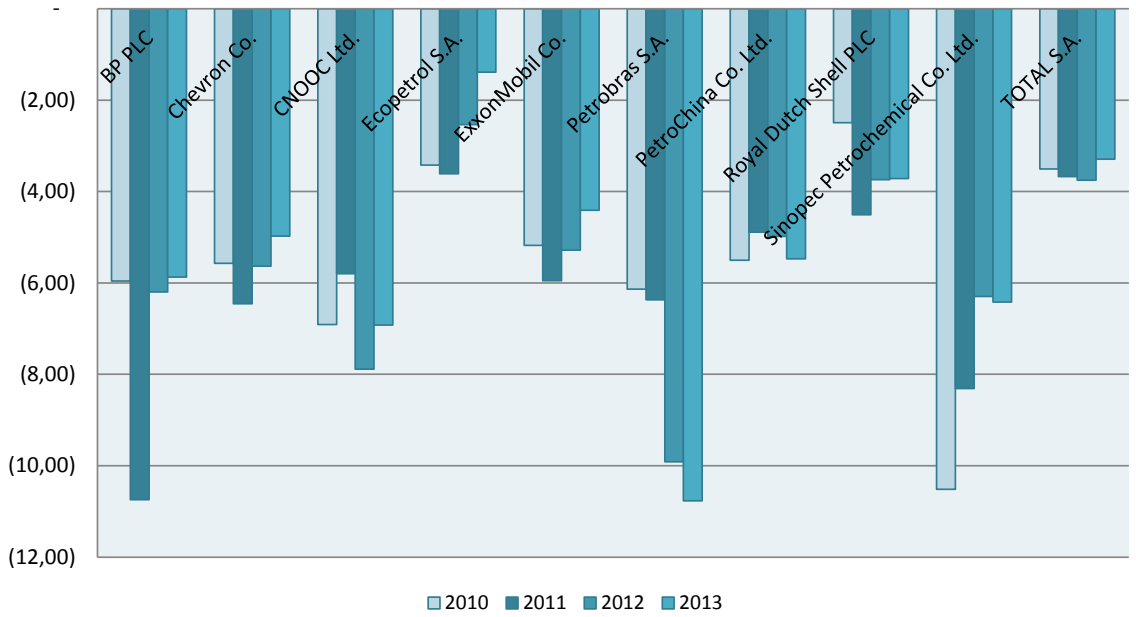

Fonte: os autores. 
O quociente de cobertura de dividendos - que inclui apenas os dividendos pagos aos acionistas, pelo fato da base de dados utilizada ser muito consolidada assumiu uma tendência crescente entre os anos 2010 e 2011 para praticamente todas as organizações, excluindo apenas as de origem chinesa (CNOOC, PetroChina e Sinopec), nas quais é possível notar uma significante redução.

Em relação a 2012 e 2013, 60\% das empresas registraram uma redução do índice, destaque para a drástica queda da Britsh Petroleum (BP) em 2012, enquanto o restante obteve um aumento, destacando a brasileira Petrobras, que quase duplicou o resultado do seu índice de 2011 para 2013. Vale ressaltar, também, que a francesa TOTAL manteve um comportamento crescente e proporcional durante os três primeiros anos analisados, tendo em 2013 uma pequena redução, fato que ocorreu às avessas com a chinesa Sinopec, a qual registrou um comportamento proporcional e visivelmente decrescente durante os três primeiros anos estudados e um crescimento irrisório em 2013.

O Gráfico 2 expõe a análise da segunda categoria de indicadores, os quocientes de qualidade do resultado, calculados a partir do índice de qualidade do resultado entre os anos 2010 e 2013.

\section{Gráfico 2 - Índice de qualidade do resultado}

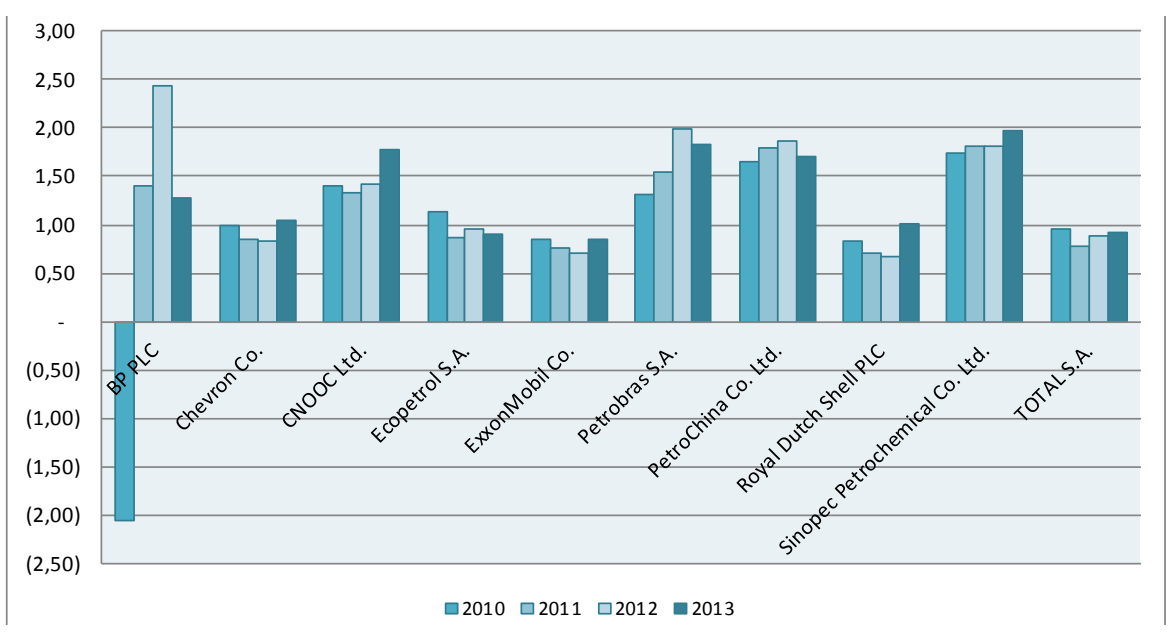

Fonte: os autores.

Em relação aos resultados obtidos no índice de qualidade do resultado, a amostra analisada, ou ao menos sua maior parte, não obteve uma particularidade ou regra. A americana Chevron e a chinesa Sinopec, por exemplo, mantiveram 
seus índices estáveis entre os anos 2011 e 2012, enquanto a também americana ExxonMobil e a anglo-holandesa Shell demonstraram uma gradativa queda em seus índices durante 2010 e 2012 e uma visível melhora em 2013. Fato que não ocorreu com a brasileira Petrobras e a chinesa PetroChina, as quais apresentaram um gradual aumento em seus indicadores durante 2010 e 2012 e uma modesta queda em 2013.

A francesa TOTAL, a chinesa CNOOC e a colombiana Ecopetrol apresentaram uma pequena queda em seus índices entre 2010 e 2011, fato que foi revertido em 2012, quando elas apresentaram um crescimento nos valores obtidos. $\mathrm{O}$ aspecto mais intrigante ocorreu com a British Petroleum (BP), a qual, em 2010, obteve um quociente negativo, fato que foi totalmente recuperado em 2011, fazendo com que em 2012 a companhia obtivesse o maior índice entre as empresas analisadas $(2,43)$, o que significa que para cada US\$ 1,00 de lucro operacional, o empreendimento gerou US\$2,43 em caixa operacional. Porém, no ano 2013, foi notória a queda no índice desta, reduzido praticamente à metade do valor obtido em 2012.

O Gráfico 3 divulga valores obtidos entre os anos 2010 e 2013, para as análises da terceira categoria de indicadores, o quociente de dispêndio de capital, calculado por meio do indicador de fluxos de caixa das atividades de investimento sobre os fluxos de caixa das atividades de financiamento.

Gráfico 3 - Índice de fluxos de caixa de investimento sobre financiamento

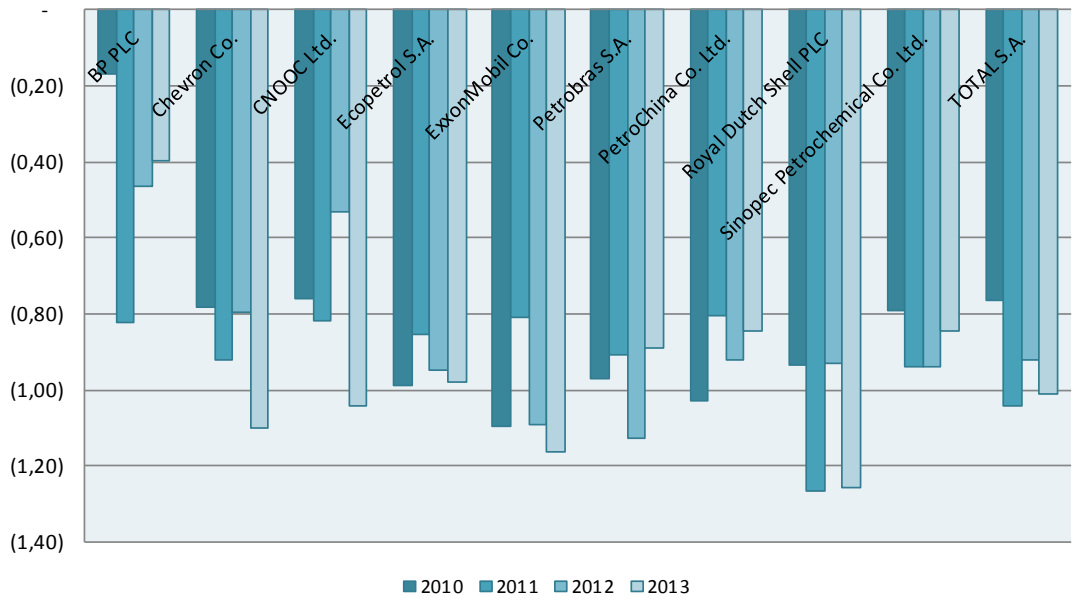

Fonte: os autores 
Entre os anos de 2010 e 2011, houve um crescimento do índice em 60\% das empresas, com destaque para a Britsh Petroleum (BP), que quadriplicou seu resultado em apenas um ano, e para a anglo-holandesa Shell, a qual também demonstrou resultados bem acima da média. Ecopetrol, ExxonMobil, Petrobras e PetroChina seguiram o caminho inverso durante o mesmo período, apresentando reduções ao invés de crescimento no referido índice.

Em relação ao ano 2012, o efeito observado foi o inverso do descrito no período anterior (2010-2011), 40\% das companhias apresentaram um crescimento no índice, fato que indica que os fluxos de caixa utilizados para investimentos se tornaram, com o passar do ano, cada vez mais superiores do que os alcançados por meio das atividades de financiamento. Em 2013, assim como em 2011, 60\% das companhias exibiram um crescimento no índice. Curiosamente, a chinesa Sinopec se manteve estável nos anos 2011 e 2012, obtendo o mesmo valor para o indicador por dois anos seguidos. Outro fato curioso que destoa da uniformidade do gráfico é o valor obtido pela anglo-holandesa Shell em 2011 e 2013. A empresa evidenciou um índice de 1,27 e 1,26, respectivamente, fato que significa que os fluxos de caixa utilizados para investimentos foram 1,27/1,26 vezes superiores aos obtidos por meio das atividades de financiamento.

O Gráfico 4 exibe a análise da quarta e da última categorias de indicador, a de retornos do fluxo de caixa, obtidos por intermédio do indicador de retorno do caixa sobre os ativos totais da companhia entre os anos 2010 e 2013.

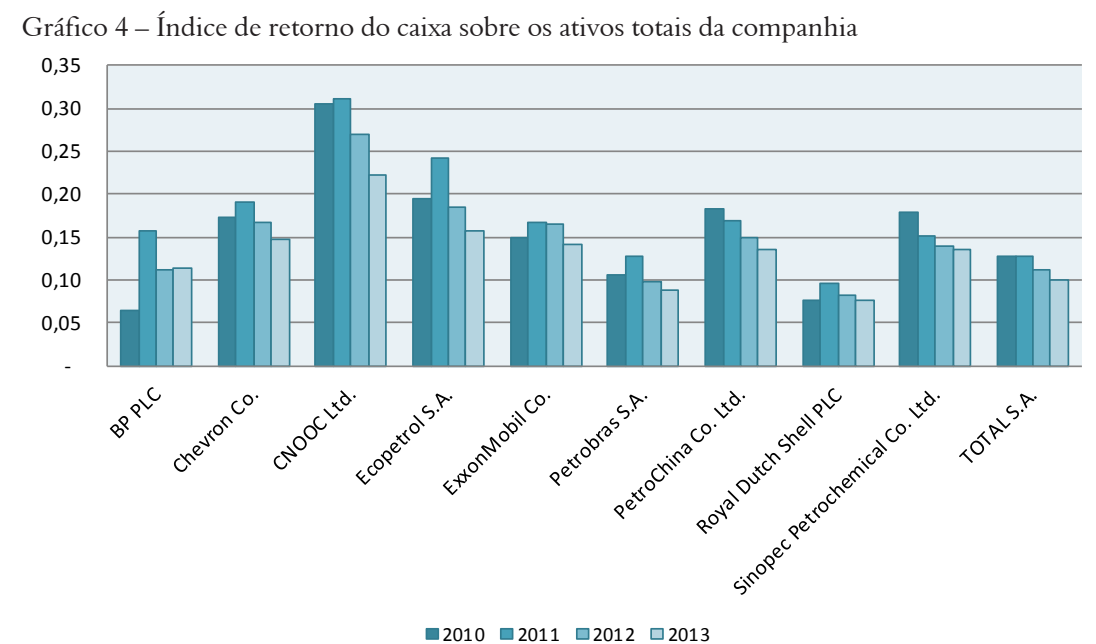

Fonte: os autores. 
O retorno do caixa sobre os ativos totais se mostrou estável para o setor em relação ao seu crescimento e posterior queda. $70 \%$ das empresas tiveram um aumento em seu índice entre os anos 2010 e 2011, seguidas de uma ligeira redução deste em 2012 e 2013. Apenas as chinesas PetroChina e Sinopec não seguiram essa tendência, já que elas demonstraram um gradual declínio do indicador ao longo dos quatro anos analisados.

A francesa TOTAL e a britânica Britsh Petroleum (BP) também destoaram da regra, pois mantiveram seus índices estáveis entre os anos 2010 e 2011 e 2012 e 2013, respectivamente. A TOTAL obteve uma taxa de 13\% durante dois anos seguidos, o que de fato significa que o ativo total, base total de investimento da empresa, proporcionou um retorno de 13\% em disponibilidades. Outro caso observado foi o fato de a anglo-holandesa Shell ter conseguido aumentar o seu índice de 0,08 para 0,10 entre 2010 e 2011, e em 2012 e 2013 ter voltado para o mesmo valor obtido em 2010, 0,08.

Pela análise desenvolvida, foi possível perceber que a amostra obedeceu a padrões semelhantes de crescimento e redução ao longo dos quatro anos observados em quase todas as categorias analisadas, para a maior parte das companhias, fato que não foi observado apenas em relação ao indicador de qualidade do resultado, no qual nenhum padrão consistente foi encontrado. Para a maior parte das companhias analisadas, 2011 foi o ano em que elas obtiveram os maiores lucros líquidos, e, consequentemente, os maiores valores de dividendos pagos aos acionistas e os maiores resultados de FCO.

Com o atual estudo, não se teve o objetivo de comparar exaustivamente o desempenho obtido pelas companhias, mas apenas evidenciar, por meio dos gráficos expostos, a interpretação dos índices obtidos mediante a DFC. Pode-se afirmar que a utilização dos referidos indicadores deve complementar os índices tradicionais de medição da capacidade de pagamento.

\section{CONCLUSÃO}

A necessidade crescente de se obterem resultados mais precisos e confiáveis faz com que as companhias busquem ferramentas que as auxiliem no processo de tomada de decisão. Existe uma permanente atenção em relação aos recursos financeiros de uma companhia, fato que torna indispensável o emprego de 
instrumentos os quais possibilitem o controle e, consequentemente, o planejamento de uma empresa.

$\mathrm{Na}$ presente pesquisa, foram mencionados e discutidos alguns dos indicadores obtidos por meio da demonstração dos fluxos de caixa, enfatizando os que relacionam o total do caixa gerado/consumido nas atividades operacionais. É importante afirmar que os referidos indicadores, bem como os demais, também sofrem limitações quando usados de maneira isolada ou para períodos muito curtos de tempo.

Quanto aos objetivos expostos durante a pesquisa, pode-se afirmar que foram alcançados, fato que comprova que a DFC é um instrumento imprescindível em relação ao gerenciamento do caixa e da real situação financeira de uma organização, assim como é possível afirmar que os indicadores financeiros obtidos por meio da DFC conseguem atingir toda a estrutura da referida demonstração, tornando as informações obtidas por meio dela mais compreensíveis.

Em relação à amostra analisada, foram selecionadas 10 companhias listadas na SEC do setor de óleo \& gás, que divulgaram anualmente suas demonstrações no formato 20-F, nos anos 2010 a 2013. Foram escolhidas as companhias mais relevantes, considerando-se seu valor de mercado.

Os dados coletados para que fosse possível calcular os indicadores propostos no estudo foram obtidos por meio da base de dados do site PFC Energy e foram estruturados por empresa, para que fosse possível analisar o comportamento dos fluxos de caixa mediante gráficos com base em planilhas do Excel.

Por intermédio das análises, foi possível perceber que a amostra obedeceu a padrões semelhantes de crescimento e redução ao longo dos quatro anos observados em quase todas as categorias analisadas, para a maior parte das companhias, fato que não foi observado apenas em relação ao indicador de qualidade do resultado, para o qual nenhum padrão consistente foi percebido.

Foi perceptível, também, que para a maior parte das companhias analisadas, 2011 foi o ano em que elas obtiveram os maiores lucros líquidos e, consequentemente, os maiores valores de dividendos pagos aos acionistas e os maiores resultados de FCO.

Pode-se afirmar que isso ocorreu em razão da alta verificada no setor em 2011, decorrente do aumento da demanda por petróleo durante o período pósrecessão seguido da decisão da OPEP de manter os cortes - implementados em 2008/2009, mas ainda em vigor na época - na produção, o que fez com que o preço médio do petróleo no referido ano disparasse. 
Eventos como a "Primavera Árabe" e o terremoto seguido por um tsunâmi ocorridos no Japão em 2011 também tiveram grande impacto no setor energético global. Ambos os fatos causaram rupturas no abastecimento de petróleo, o que o levou a bater recordes em relação ao preço.

Porém, dados referentes ao consumo mundial de energia afirmam que após o pico observado no consumo durante o período pós-recessão, o setor não conseguiu sequer manter o ritmo do seu crescimento, registrando, assim, valores bem abaixo nos anos seguintes, fato que explica o pico nos resultados obtidos durante o ano 2011.

Recomenda-se, para futuros estudos, a utilização dos indicadores obtidos por meio da DFC aplicados aos demais setores da economia, assim como pesquisas que comparem a relevância dos referidos índices com outros obtidos por meio das demais demonstrações financeiras.

\section{REFERÊNCIAS}

ALVES, L. C. O.; MARQUES, J. A. V. C. Identificação das fases do ciclo de vida de empresas através da análise das demonstrações dos fluxos de caixa. Revista de Administração e Contabilidade da Unisinos, v. 4, n. 3, p. 249-262, set./dez. 2007.

\section{ANDRADE, M. M. Como preparar trabalhos para cursos de pós- graduação: noções práticas. 5. ed. São Paulo: Atlas, 2002.}

ASSAF NETO, A.; SILVA, C. A. T. Administração do Capital de Giro. 2. ed. São Paulo: Atlas, 1997.

BARAC, Z. Cash flow ratios vs. accrual ratios: Empirical research on incremental information content. The Business Review Cambridge, v. 15, n. 2, p. 206-213, set. 2010.

BARBOSA, J. D. S. et al. A relevância da demonstração do fluxo de caixa DFC) no planejamento financeiro das organizações. In: SEMEAD - SEMINÁRIOS EM ADMINISTRAÇÃO, 13., 2010. São Paulo. Anais... São Paulo, 2010.

BASTO, D. D. et al. A relação entre o retorno das ações e as métricas de desempenho: evidências empíricas para as companhias abertas no Brasil. Revista de Gestão USP, São Paulo, v. 16, n. 3, p. 65-79, jul./set. 2009.

BEAVER, W. H. Alternative accounting measures as predictors of failure. The Accounting Review, v. 43, n. 1, p. 113-122, jan. 1968. 
BORGES, M. S. D.; NUNES, S. C. D.; ALVES, M. T. V. D. A demonstração dos fluxos de caixa e sua contribuição para uma tomada de decisão mais informada. Revista Universo Contábil, Blumenau, v. 8, n. 1, p. 141-158, jan./mar. 2012.

BRITISH PETROLEUM PLC. BP statistical review of world energy june 2011. London, UK, jun. 2011. Disponível em: < http://www.bp.com/liveassets/bp internet/china/bpchina_english/STAGING/local_assets/downloads_pdfs/statistical_ review_of_world_energy_full_report_2011.pdf>. Acesso em: 06 jan. 2013.

BRITISH PETROLEUM PLC. BP statistical review of world energy june 2012. London, UK, jun. 2012. Disponível em: < http://www.bp.com/liveassets/bp internet/china/bpchina_english/STAGING/local_assets/downloads_pdfs/statistical_ review_of_world_energy_full_report_2012.pdf>. Acesso em: 06 jan. 2013.

BRAGA, R.; MARQUES, J. A. V. C. Avaliação da liquidez das empresas através da análise da demonstração de fluxos de caixa. Revista Contabilidade \& Finanças, São Paulo, v. 14, n. 25, p. 6-23, jan./abr. 2001.

DECHOW, P. M.; KOTHARI, S. P.; WATTS, R. L. The relation between earnings and cash flows. Journal of Accounting \& Economics, v. 25, n. 2, p. 133-168, ago. 1998.

DUHOVNIK, M. Improvements of the cash-flow statement control function in financial reporting. Zbornik Radova Ekonomskog Fakulteta u Rijeci, v. 26, n. 1, p. 123-150, 2008.

FARSHADFAR, S.; MONEM, R. Further evidence on the usefulmess of direct method cash flow components for forecasting future cash flows. The International Journal of Accounting, v. 48, n. 1, p. 111-133, mar. 2013.

FERRAES NETO, F. A relação da logística com a administração financeira e seus impactos nos índices financeiros de uma organização. Revista FAE, v. 5, n. 3, p. 41-49, set./dez. 2002.

FRANCIS, R. N. Out-of-sample cash flow prediction and cash distributions to shareholders. Advances in Accounting, Incorporating Advances in International Accounting, v. 27, n. 1, p. 1-9, jun. 2011.

GIL, A. C. Métodos e técnicas de pesquisa social. 5. ed. São Paulo: Atlas, 1999.

GITMAN, L. J. Princípios de administração financeira. 7. ed. São Paulo: Harbra, 1997. 
GIVOLY, D.; HAYN, C. The changing time-series properties of earnings, cash flows and accruals: Has financial reporting become more conservative? Journal of Accounting and Economics, v. 29, n. 3, p. 287-320, jun. 2000.

JOOSTE, L. Cash flow ratios as a yardstick for evaluating financial performance in african business. Managerial Finance, v. 32, n. 7, p. 569-576, 2006.

LARGAY III, J. A.; STICKNEY, C. P. Cash flows, ratio analysis and the W. T. Grant company bankruptcy. Financial Analysts Journal, v. 36, n. 4, p. 51-54, jul./ago. 1980.

MACEDO, M. A. S. et al. Análise do impacto da substituição da DOAR pela DFC: um estudo sob a perspectiva do value-relevance. Revista Contabilidade \& Finanças, São Paulo, v. 22, n. 57, p. 299-318, set./dez. 2011.

PFC ENERGY. The definitive annual ranking of the world's largest listed energy firm. Washington, DC, jan. 2013. Disponível em: < http://www.pfcenergy. com/ /media/Files/Public\%20Files/PFC\%20Energy\%2050/PFC50_2013.pdf>. Acesso em: 03 out. 2013.

RUSHINEK, A.; RUSHINEK, S. F. Using financial ratios to predict insolvency. Journal of Business Research, v. 15, n. 1, p. 93-100, fev. 1987.

SILVA, M. B. D.; GRIGOLO, T. M. Metodologia para iniciação científica à prática da pesquisa e da extensão II. Caderno Pedagógico. Florianópolis: Udesc, 2002.

VERGARA, S. C. Projetos e relatórios de pesquisa em administração. 2. ed. São Paulo: Atlas, 1998.

XU, P. T. Managerial incentives and a firm's cash flow sensitivities. International Review of Economics and Finance, v. 27, p. 80-96, jun. 2012.

\section{COMO CITAR ESTE ARTIGO:}

ABRAHÃO, Sophie de Souza; CARVALHO, Márcia da Silva; MARQUES, -1 José Augusto Veiga da Costa. Análise do Desempenho Financeiro das Empresas do Setor de Óleo \& Gás Através do Comportamento dos Fluxos de Caixa no Período de 2010-2013. RACE, Revista de Administração, Contabilidade e Economia, Joaçaba, Ed. Unoesc, v. 14, n. 3, p. 1063-1090, set./dez. 2015. Disponível em: < http://editora.unoesc.edu.br/index.php/race> . Acesso em: dia/ mês/ano. 
Abrahão, S. de S., Carvalho, Márcia da S., \& Marques, J. S. V. da C. (2015). Análise do Desempenho Financeiro das Empresas do Setor de Óleo \& Gás Através do Comportamento dos Fluxos de Caixa no Período de 2010-2013. RACE, Revista de Administração, Contabilidade e Economia, 14(3), 1063-1090. Recuperado em: dia/mês/ ano, de http://editora.unoesc.edu.br/index.php/race 
